\title{
Association of the genetic variants in the Endoplasmic reticulum aminopeptidase 2 gene with ankylosing spondylitis susceptibility
}

Mehrdad Ebrazeh

Islamic Azad University Bonab Branch

Fatemeh Ezzatifar

Mazandaran University of Medical Sciences

Shahram Torkamandi

Urmia University of Medical Sciences

Fatemeh Sadat Mohammadi

Mashhad University of Medical Sciences

Sevda Salimifard

Mashhad University of Medical Sciences

Maryam Hemmatzadeh

Tabriz University of Medical Sciences

\section{Saeed Aslani}

Tehran University of Medical Sciences

Farhad Babaie

Urmia University of Medical Sciences

Gholamreza Azizi

Alborz University of Medical Sciences

Farhad Jadidi-Niaragh

Tabriz University of Medical Sciences

Arezoo Gowhari-Shabgah

Bam university of medical sciences

Hamed Mohammadi ( $\nabla$ mohamadi.h86@gmail.com )

Alborz University of Medical Sciences https://orcid.org/0000-0002-0736-6211

Research article

Keywords: Endoplasmic reticulum aminopeptidase 2, Ankylosing spondylitis, Human leukocyte antigenB27, Single nucleotide polymorphisms, Inflammation

Posted Date: August 25th, 2020 
DOI: https://doi.org/10.21203/rs.3.rs-41840/v2

License: (c) (1) This work is licensed under a Creative Commons Attribution 4.0 International License. Read Full License

Version of Record: A version of this preprint was published at International Journal of Rheumatic Diseases on February 7th, 2021. See the published version at https://doi.org/10.1111/1756-185X.14079. 


\section{Abstract}

Background: Genetic polymorphisms in the Endoplasmic reticulum aminopeptidase (ERAP) 2 gene has been attributed with the Ankylosing spondylitis (AS) etiopathogenesis. Here we assessed the association of ERAP2 gene single nucleotide polymorphisms (SNPs) with AS predisposition in Iranian patients and determined their effect on the inflammatory state of the patients.

Methods: For genotyping of rs2548538, rs2287988, and rs17408150 SNPs using Real-time allelic discrimination approach, DNA was extracted from the whole blood of 250 AS patients and 250 healthy subjects. RNA of the peripheral blood mononuclear cells (PBMCs) was separated, cDNA was synthesized, and transcriptional levels of cytokines, including interleukin (IL)-17A, IL-23, IL-10, and transforming growth factor (TGF)- $\beta$ were measured. Enzyme-linked immunosorbent assay (ELISA) was used to measure the serum concentration on the cytokines.

Results: Three ERAP2 gene SNPs were not associated significantly with AS risk. Nonetheless, rs2287988 and rs17408150 SNPs showed statistically significant association with susceptibility to the disease in those AS subjects who were positive to Human leukocyte antigen (HLA)-B27. Transcriptional level and serum concentration of IL-17A and IL-23 were higher, while those of IL-10 were lower in both AS patients and HLA-B27 positive patient group relative to control group. Nevertheless, ERAP2 gene SNPs in the HLAB27 positive AS patients did not affect the transcriptional level and serum concentration of cytokines.

Conclusions: ERAP2 gene rs2287988 and rs17408150 SNP are associated with susceptibility to AS, but they probably are not determining the levels of IL-17A, IL-23, and IL-10 in this disease.

\section{Background}

Ankylosing spondylitis (AS) is a chronic autoimmune disease and is characterized by involvement of spine and sacroiliac joints that causes spine deformities, increased disability, and mortality (1). A bulk of research has suggested a significant role for genetic variations in the etiology and pathogenesis of AS (2, $3)$, in spite of the remarkable involvement of environmental factors as well as aberrant epigenetic regulations (4-8). The pathogenesis of AS is complicated, and earlier research concentrated on the misfolding of human leukocyte antigen (HLA)-B27 molecule in the disease susceptibility; however, genetic studies have proposed that HLA-B27 accounts for a small part of the overall AS risk (9). Epidemiological investigations has shown that HLA-B27 gene is carried by almost $90 \%$ of AS patients, while only $1-5 \%$ of individuals carrying the HLA-B27 gene will be affected with AS in the future (10). These observations imply to the involvement of non-HLA genes in the AS risk.

Endoplasmic reticulum aminopeptidase (ERAP) 2 is an enzyme that belongs to zn-metallopeptidase family and the corresponding gene is located on the chromosome $5 q 15$. This enzyme is found within the endoplasmic reticulum (ER) that is involved in priming peptides during the antigen presentation pathway via the major histocompatibility complex (MHC) class I (11). In comparison to ERAP1, data lack about the attribution of ERAP2 polymorphisms with AS predisposition $(4,12,13)$. A number of genetic 
polymorphisms in the ERPA2 gene has been attributed to the alterations in the protein structure and function. The AS protective ERAP2 gene SNP, rs2248374 (14), alters the splicing site in the exon 10, leading to synthesis of a lengthy exon 10 transcript (15). As a loss-of enzyme polymorphism, rs2248374 cause no protein expression of ERAP2 and has been attributed with downregulation of MHC class I molecule levels on the cell surface (15). Another variant is rs2549782 SNP, that confers a modulation in the specificity as well as functional velocity of the enzymatic activity of ERAP2 $(14,16)$. ERAP2 gene rs2549782 SNP shows a linkage disequilibrium (LD) with other ERPA2 SNPs, including rs2548538, rs2287988, rs1056893, and rs2248374, which are marker SNPs that constitute A and B haplotypes that are associated with protein expression of ERAP2 (15). In addition, ERAP2 gene rs 17408150 leads to substitution of a T with an A at codon 669 (p.Leu669GIn) that alters the leucine residue to glutamine, resulting in a significant effect on the ERAP2 enzyme function (17).

Association of ERAP1 SNPs has already been reported with AS susceptibility in Iranian patients during our previous works (18-21). Furthermore, we recently indicated the association ERAP2 gene SNPs AS susceptibility in the HLA-B27 positive subjects (22). With respect to the involvement of genetic variations in the alteration of ERAP2 enzyme, it seems that evaluation of such SNPs worth studying. Hence, this study aims to determine the association ERAP2 gene rs2548538, rs2287988, and rs17408150 SNPs, for the first time to the best of our knowledge, in an Iranian AS population. Furthermore, the possible role of these SNPs was investigated in the controlling of inflammatory and immunomodulatory mediators in the AS disease.

\section{Methods}

\section{Study participants}

In this investigation, 250 individuals with AS disease and 250 persons as healthy controls were included (Table 1). The 1984 modified New York Criteria was exerted to diagnose AS disease (23). Healthy controls had no background diseases as well as history of AS or other autoimmune diseases neither in them nor family members and were matched for age and gender with the case group. AS patients were selected from the individuals recruited to Shahid Rajaee and Emam Reza Hospitals affiliated with Alborz and Tabriz University of Medical Sciences, Iran and outpatient Rheumatology Clinics of the Tabriz University of Medical Sciences during 2015 to 2020 . The approvement of the study protocol was received from the local Ethical Review committee in Alborz University of Medical Sciences (Permission No.

IR.ABZUMS.REC.1399.051). Prior to sampling, the written informed consent forms were obtained from all AS patients and healthy individuals. All study subjects were assessed for the HLA-B27 positivity and the clinical condition of the patients were determined by Bath AS Disease Activity Index (BASDAI), Bath AS Functional Index (BASFI), Bath AS Metrology Index (BASMI), Bath AS Global Score (BASG), and AS quality of life (ASQoL). Using venipuncture, about $10 \mathrm{ml}$ of venous blood was taken from all participants.

\section{ERAP2 SNPs genotyping}


To obtain DNA from venous blood samples, the QIAamp DNA Mini Kit (Qiagen, Germany) was used based on the company's instructions. Afterwards, in order to genotype the study participants for ERAP2 gene rs2548538, rs2287988, and rs17408150 SNPs, Real-time was exerted using TaqMan assays (Applied Biosystems, Foster City, USA) and StepOnePlus Real-Time PCR system (Applied Biosystems, Foster City, USA). To perform Real-time genotyping, the PCR reactions mixture was comprised of $5 \mu$ l TaqMan Master Mix (containing Taq DNA polymerase and dNTPs; Applied Biosystems, Foster City, USA), $0.5 \mu$ I TaqMan Genotyping Assay mix containing primers and probes (Applied Biosystems, Foster City, USA), $2 \mu$ of genomic DNA (20 ng/ $\mu \mathrm{l}$ ), and distilled $\mathrm{H}_{2} \mathrm{O}$ (final volume of $15 \mu \mathrm{l}$ in each tube). The thermocycling settings of the PCR amplification were initial heating for $60^{\circ} \mathrm{C}$ for 45 seconds followed by $95^{\circ} \mathrm{C}$ for 10 mins, then 40 amplification cycles in $95^{\circ} \mathrm{C}$ for 15 seconds and $60^{\circ} \mathrm{C}$ for 60 seconds, and finally $60^{\circ} \mathrm{C}$ for 30 seconds.

\section{PBMC separation, RNA isolation, and CDNA synthesis}

PBMCs were isolated from the peripheral blood using Ficoll/Hypaque (Lymphodex, inno-Train, Kronberg, Germany) density-gradient centrifugation. Extraction of RNA from PBMCs was carried out exerting the Trizol total RNA extraction kit (GeneAll, Korea) based on the producer's guidelines. Synthesizing of the complementary DNA (cDNA) from the extracted RNA samples was conduced by the BioFact ${ }^{\text {TM }}$ RT Series cDNA Synthesis Kit (Daejeon, Korea), conforming the company's protocols.

\section{Quantitative Real-time PCR}

In order to assess the mRNA expression levels of inflammatory and immunomodulatory cytokines, including IL-17A, IL-23, IL-10, and transforming growth factor (TGF)- $\beta$, quantitative Real-time PCR was exerted using the Rotor-Gene Q Real-time PCR System machine (Qiagen, USA) by the SYBR Green PCR Master Mix. The characteristics of the primers employed for Real-time mRNA transcript quantification are listed in table 2 . We randomly selected 80 AS patients and 80 control subjects for mRNA expression analysis. For quantitative Real-time, each reaction mixture contained SYBR Green Master Mix $12.5 \mu \mathrm{l}$, cDNA $4.5 \mu \mathrm{l}$, forward and revers primer $1 \mu \mathrm{l}$ each, and $\mathrm{H}_{2} \mathrm{O} 6 \mu \mathrm{l}$ to reach a final volume of $25 \mu \mathrm{l}$. The thermocycling PCR conditions were: $50^{\circ} \mathrm{C}$ for 2 minutes, $95^{\circ} \mathrm{C}$ for 10 minutes, then 40 cycles of $95^{\circ} \mathrm{C}$ for 30 seconds, $60^{\circ} \mathrm{C} 30$ seconds, and $72^{\circ} \mathrm{C}$ for 30 seconds. To compute the relative mRNA transcript of target genes, the comparative $C_{T}$ method, as explained by Schmittgen and Livak (24), was used. The relative expression levels of target genes were determined through normalization in accordance to the mRNA level of the corresponding housekeeping gene ( $\beta$-Actin). The mathematical formula to compute the relative mRNA expression in each subject was $2^{-D D C t}$.

\section{Serum concentration of cytokines}

Like quantitative mRNA expression analyses, serum samples from the venous blood of the same subjecst were used to determine the concentration of the cytokines. Hence, the enzyme linked immunosorbent assay (ELISA) technique was applied to determine the serum concentrations of IL-23, IL-17A, IL-10, and TGF- $\beta$ in 80 patients and 80 controls. The optical density was determined using commercial kit 
(Invitrogen, Thermo Fisher Scientific, San Diego, CA, USA) and determination of the optical density (OD) in each well by an ELISA reader (Tecan Spectra, Austria).

\section{Statistical analysis}

The baseline features of the patient and control groups were determined by descriptive statistical analysis. Determination of the associations between the ERAP2 gene SNPs and risk of AS was analyzed by Pearson's chi square ( $\chi 2)$ as well as Logistic Regression, and the association level was determined through measuring the odds ratios (OR) and corresponding $95 \%$ confidence intervals (CI). The LD for SNP pairs, the haplotypic analysis, and examination of the genotype distribution of SNPs in the control group to meet the Hardy-Weinberg Equilibrium (HWE) were carried out using the SHEsis online tool (25). Adjusting of the $P$ values was carried out by Benjamini-Hochberg Method. Testing for the normal distribution of scale data (mRNA expression, serum concentration, and clinical indexes) was accomplished by the Kolmogorov-Smirnov test. To approximate the significance of difference in the mRNA expression and serum concentration of the cytokines between study groups, the mean comparisons were done by the non-parametric Mann-Whitney U-test. Furthermore, the Kruskal-Wallis test was used to perform mean comparison of data among patients with three genotypes for SNPs. Data presentation were done through average \pm standard deviation (SD) for scale data or by percentage for nominal data. Data analysis was accomplished by SPSS software v.25.0 (IBM SPSS Inc., USA) and graphing of data by bar charts was conducted using GraphPad PRISM software (version 8.00; GraphPad Software, Inc., San Diego, CA, USA).

\section{Results}

\section{Baseline features of the participants}

The baseline and laboratory indexes of the study population are listed with detail in the Table 1 . The male/female distribution of the study subjects in the AS and control groups was $53(21.2 \%) / 197$ (78.8\%) and $45(18 \%) / 205(82 \%)$, respectively. The age of the AS and control groups was $38.50 \pm 8.80$ and $37.62 \pm 7.40$, respectively. The matching of two study groups for age $(P>0.05)$ and sex $(P>0.05)$ was observed. HLA-B27 was observed to be positive in 202 (80.8\%) AS patients and 18 (7.2\%) healthy controls $(P<0.0001)$. Moreover, the $C$-reactive protein $(C R P)$ level in the case group $(3.14 \pm 2.27)$ was significantly higher $(P<0.0001)$ relative to the control group $(1.27 \pm 0.95)$.

\section{Association test of ERAP2 polymorphisms}

The frequency distribution pattern of the genotypes for ERAP2 gene rs2548538 ( $P=0.830)$, rs2287988 $(P=0.443)$, and rs17408150 ( $P=0.165)$ SNPs in the healthy control group adhered to the HWE. In the total population analysis, results revealed that all three SNPs did not associate significantly with risk of AS (Table 3). That notwithstanding, when the HLA-B27 positive AS patients and the control group were compared, rs2287988 and rs17408150 SNPs showed statistically significant association with AS risk (Table 4). 
For rs2287988, there was significant association in the minor $\mathrm{G}$ allele and $\mathrm{GG}$ genotype. The $\mathrm{G}$ allele was represented in $45.7 \%$ of the HLA-B27 positive AS patients and in $38.4 \%$ of the healthy controls $(O R=1.35$, $95 \% \mathrm{Cl}=1.03-1.76, P=0.023)$. The GG genotype was frequently presented in the HLA-B27 positive AS patients relative to controls $(20.3 \%$ vs. $13.6 \%)$, and the difference was statistically significant (OR= 1.91 , $95 \% \mathrm{Cl}=1.09-3.35, P=0.022)$.

In case of rs 17408150 , it was observed that the $C$ allele had significant association with higher risk of AS in the HLA-B27 positive patients (OR=1.39, 95\%Cl=1.06-1.81, $P=0.013)$. The AA genotype was represented in the HLA-B27 positive AS group (21.8\%) higher than the controls (17.2\%); hence the AA genotype was associated significantly with increased AS risk $(\mathrm{OR}=2.13,95 \% \mathrm{Cl}=1.19-3.82, P=0.010)$. The heterozygote AT genotype had statistically significantly difference in the distribution between HLA-B27 positive AS cases versus control group (OR=1.91,95\%Cl=1.19-3.06, $P=0.007)$. It was observed that the dominant model of AA+AT vs. TT for rs 17408150 SNP had significant association with the higher AS risk $(\mathrm{OR}=1.96,95 \% \mathrm{Cl}=1.24-3.10, P=0.003)$ in the AS group with positive HLA-B27.

\section{Frequency of the haplotype}

Regarding the haplotypic analysis (rs2548538 A/T, rs2287988 A/G, and rs17408150 A/T), it was detected that four haplotypes had significant association with AS risk. While AAA (OR=2.13, 95\% Cl= 1.25-4.31, $P=$ $0.014)$ and $A A T(O R=2.85,95 \% \mathrm{Cl}=1.50-05.40, P=0.0083)$ haplotypes were associated with increased AS risk, the AGA (OR= $0.86,95 \% \mathrm{Cl}=0.47-0.82, P=0.005)$ and TAT $(\mathrm{OR}=0.57,95 \% \mathrm{Cl}=0.31-0.75, P=0.004)$ haplotypes were associated with decreased risk of AS (Table 5).

\section{Linkage disequilibrium test}

The structure of SNP pairs in the LD block according to the SNP sequence of rs2548538, rs2287988, and rs 17408150 are shown in the figure 1. The $D \otimes$ value between rs 2548538 and rs 2287988 SNPs was $55 \%$ and between rs 2548538 and rs 17408150 SNPs was $81 \%$. Nonetheless, a partially stronger linkage was detected when only the HLA-B27 positive patients were included in the analysis ( $D Q=56 \%$ and $87 \%$, respectively, for rs2548538-rs2287988 and rs2548538-rs17408150). However, the $r^{2}$ values indicated no remarkable LD between SNP pairs.

\section{mRNA expression of cytokines}

The mRNA transcription level of IL-17A (fold change $[\mathrm{FC}]=2.85, P=0.0001$, Figure 2.a) and IL-23 $(\mathrm{FC}=1.63$, $P=0.0084$, Figure 2.b) had upregulated levels in the PBMCs obtained from AS patients in relation to healthy subjects. However, there was significant underexpression of the mRNA of IL-10 (FC=0.43, $P=0.0024$, Figure 2.c) in the PBMCs obtained from AS patients relative to the healthy subjects. The mRNA expression of TGF- $\beta$ was lower non-significantly in the case group relative to the control group $(F C=0.89$, P> 0.05, Figure 2.d). The mRNA expression of all four cytokines had no significant difference among AS patients with three genotypes for rs2287988 and rs17408150 SNPs (Figure 2 and Supplementary Table 1). 
Transcript levels of IL-17A ( $F C=3.00, P=0.0001$, Figure 3.a) and IL-23 (FC=1.70, $P=0.0084$, Figure 3.b) had upregulated levels in the PBMCs obtained from AS patients positive for HLA-B27 gene relative to the healthy subjects. Conversely, the transcript level of IL-10 ( $F C=0.41, P=0.001$, Figure 3.c) was significantly lower in the PBMCs obtained from AS patients positive for HLA-B27 relative to healthy subjects. The mRNA expression of TGF- $\beta$ had no significant difference between HLA-B27 positive AS patients and the normal controls ( $F C=0.82, P>0.05$, Figure 3.d). The mRNA expression of all cytokines had no significant difference among the AS patients positive for HLA-B27 carrying three different genotypes for rs2287988 and rs17408150 SNPs (Figure 3 and Supplementary Table 1).

\section{Serum concentration of cytokines}

The serum concentrations of IL-17A ( $46.50 \pm 13.10$ vs. $19.56 \pm 6.48, P=0.0001$, Figure $4 . a)$ and IL-23 (388.9 $\pm 38.78 v s .200 .2 \pm 24.88, P=0.0001$, Figure 4.b) were increased in the AS group relative to normal control group. However, the serum concentration of IL-10 was significantly lower in the AS group compared with the control group ( $1.89 \pm 0.18 v s$. $3.68 \pm 1.10, P=0.0015$, Figure 4.c). However, the difference in the serum concentration of TGF- $\beta$ was not statistically significant between AS group and the control group (20.4 \pm 4.51 vs. $23.4 \pm 4.21, P>0.05$, Figure $4 . d)$. The serum concentration of all cytokines had no significant difference among the AS cases positive for HLA-B27 harboring three different genotypes for rs2287988 and rs17408150 SNPs (Figure 4 and Supplementary Table 2).

The serum concentrations of IL-17A (49.11 \pm 14.21 vs. $19.56 \pm 6.48, P=0.0001$, Figure $5 . a)$ and IL-23 (395.4 \pm 39.7 vs. $200.2 \pm 24.88, P=0.0001$, Figure 5.b) were higher in the AS patients positive for HLA-B27 relative to normal controls. In contrast, the serum concentration of IL-10 was significantly lower in the HLA-B27 positive AS group compared with the control group (1.75 \pm 0.14 vs. $3.68 \pm 1.10, P=0.0017$, Figure 5.c). However, the difference in the serum concentration of TGF- $\beta$ was not statistically significant between HLA-B27 positive AS cases and the control group (19.7 $\pm 4.47 v s .23 .4 \pm 4.21, P>0.05$, Figure 5.d). The serum concentration of all cytokines had no significant difference among the AS cases positive for HLA-B27 carrying three different genotypes for rs2287988 and rs17408150 SNPs (Figure 5 and Supplementary Table 2).

\section{Association of the genotypes and clinical manifestations}

The ERAP2 gene rs2548538, rs2287988, and rs17408150 polymorphisms were investigated in association with clinical features of AS patients. It was observed that none of the characteristics of the AS patients, including CRP, disease duration, BASDAI, BASFI, BASG, and ASQoL scores had significant association with ERAP2 gene polymorphisms (Table 6). Moreover, analysis of the association of the ERAP2 gene rs2548538, rs2287988, and rs 17408150 SNPs with the mentioned clinical manifestations in the HLA-B27 positive AS patients, resulting in no significant association.

\section{Discussion}


To date, large scale analyses have found over 60 genetic loci for AS risk, even though a bulk of investigations have assigned a large proportion of genetic-related risk of AS to the HLA-B27 gene $(3,26)$. There is paucity of investigations on the SNPs of the ERAP2 gene in the context of AS risk. Herein, the second survey by our group is trying to investigate the associations of ERAP2 gene polymorphisms with the risk of AS in an Iranian population. Additionally, the possible alteration of inflammatory and immunomodulatory cytokines by the ERAP2 gene rs2548538, rs2287988, and rs 17408150 polymorphisms was investigated.

ERAP2 gene association with AS was detected after identification of ERAP1 gene association with AS (12). Both ERAP1 and ERAP2 genes are found on the chromosome 5, which are structured in an inverse direction and share a common intergenic sequence (27). Studies have found a haplotype in association with AS that are constituted with both ERAP1 and ERAP2 polymorphisms $(28,29)$. On the other hand, ERPA2 polymorphisms generate two main haplotypes, namely haplotype $A$ and $B$; the haplotype $A$ results in protein expression ERAP2, while the haplotype $B$ cause no protein expression of ERAP2. The prevalence of both haplotypes $A$ and $B$ have been reported to be similar (approximately 50\%), and therefore about $25 \%$ of the individuals are haplotype $B$ homozygous and have no expression of ERAP2 (15). Lack of ERAP2 expression in haplotype $B$ is because of the ERAP2 gene rs2248374 polymorphism that influences on the RNA stability (15). It has been reported that there is a strong LD between haplotypes A and B of ERAP2 SNPs, which can be involved in the immune evasion of trophoblasts (30). Lack of ERAP2 expression has been proposed to be protective in AS and other inflammatory disorders (31). Currently, the are little data with respect to the association of ERAP2 gene rs2548538, rs2287988, and rs 17408150 polymorphisms in AS disease, and our analyses revealed no association of these SNPs with AS risk. However, we noticed that, while AAA $(O R=2.13)$ and $A A T(O R=2.85)$ haplotypes were associated with higher AS risk, the AGA $(O R=0.86)$ and TAT $(O R=0.57$,) haplotypes were associated with lower risk of AS. In addition, there was a LD between rs2548538 and rs2287988 SNPs and between rs2548538 and rs 17408150 SNPs. Interestingly, a partially stronger linkage was detected when only the HLA-B27 positive AS group was included in the analysis.

According to studies, the association of ERAP2 with AS seems to be independent of HLA-B27 $(14,32)$. ERAP2 has been reported to impress directly the $B \star 2705$ peptidome, removing a number of ligands containing N-terminal basic residues, leading to promoted levels of nonamers by the increased activity of ERAP1 (33). Based on the level of ERAP1 trimming activity, the influences of ERAP2 on B27 peptidome could be altered (34). A study indicated that ERAP2 gene rs2248374 SNP was particularly associated with Psoriatic arthritis risk in the subjects negative for HLA-B27 (35). We observed that ERAP2 gene rs2287988 and rs17408150 polymorphisms were associated with increased risk of the disease in the AS patients positive for HLA-B27. In addition, we previously reported the ERAP2 gene rs2910686 SNP association with AS risk in patients positive for the HLA-B27 (22). Further evidence is required to conclusively determine the ERAP2 involvement in collaboration with HLA-B27 in AS pathogenesis.

The overall effect of ERAP2 on the conformation of HLA-B27 have not fully been determined. A study reported that ERAP2 expression did not significantly impress the expression of the folded as well as 
unfolded HLA-B27 molecules, markers of ER stress, and the expression of proinflammatory cytokines (36). On the other side, a study demonstrated that lack of ERAP2 triggered upregulation of free heavy chain (FHC)-B27 molecule and promotion of the unfolded protein response (UPR) pathway in patients (37). The FHC-B27 molecules has been reported to stimulate UPR in the antigen presenting cells (APCs) like macrophages, which may result in increased generation and release of IL-23 (38). APCs presenting FHC-B27 molecules can promote the differentiation and expansion of Thelper (Th) 17 cells. Cells presenting FHC-B27 molecules can trigger the release of IL-17A from Th17 cells. IL-23 produced by APCs may bind to the IL-23 receptor (IL-23R) on the Th17 cells, resulting in further production of IL-17 (39). Our previous investigation indicated that the transcriptional levels as well as serum concentrations of IL-17A, IL-23, tumor necrosis factor (TNF)- $a$, and interferon (IFN)-y were not different among AS subjects positive for HLA-B27 carrying different genotypes of ERAP2 gene rs2910686 polymorphism (which had association with higher AS risk in the AS group positive for HLA-B27) (22). As such, the current study indicated that transcriptional levels as well as serum concentrations of IL-17A, IL-23, IL-10, and TGF- $\beta$ were not significantly different among AS subjects positive for HLA-B27 harboring different genotypes of the AS-associating rs2287988 and rs 17408150 SNPs of ERAP2 gene. In addition, no association was found between clinical manifestations of the AS patients and ERAP2 gene polymorphisms. Taken together, it appears that although HLA-B27 affects on the association of ERAP2 gene rs2287988 and rs 17408150 SNPs with AS risk, these ERAP2 polymorphisms might not be involved in the alteration of HLA-B27 and, hence, the inflammatory settings in the AS disease.

\section{Conclusion}

All in all, here we, for the first time, evaluated the association between ERAP2 gene rs2548538, rs2287988, and rs17408150 SNPs and the risk of AS in the Iranian patients. The results indicated that although ERAP2 gene SNPs had no association with AS risk, but rs2287988 and rs17408150 SNPs had association with promoted AS risk in the subjects positive for HLA-B27. That notwithstanding, these SNPs were not associated with the transcriptional levels or serum concentrations of the inflammatory or immunomodulatory cytokines. Although we tried to evaluate the involvement of ERAP2 polymorphisms in AS susceptibility in two studies, further evaluations of this gene, particularly in the haplotype analysis, need to be carried out to clarify the bona fide involvement of ERAP2 SNPs in the etiology and pathogenesis of AS.

\section{Declarations}

\section{Ethics approval and consent to participate}

The approvement of the study protocol was received from the local Ethical Review committee in Alborz University of Medical Sciences (Permission No. IR.ABZUMS.REC.1399.051) and written informed consent forms was taken by all subjects.

\section{Research involving human subjects and/or animals}


Research carried out here were in compliance with the Helsinki Declaration. The protocol of this study was approved by the Human Research Ethics Committee from the Alborz University of Medical Sciences, Karaj, Iran (Permission No. IR.ABZUMS.REC.1399.051). Written informed consent forms were obtained from patients and healthy controls before blood taking.

\section{Consent to publish}

All authors read the manuscript and consent for its publication.

\section{Availability of data and materials}

The data that support the findings of this study are available on request from the corresponding author. The data are not publicly available due to privacy or ethical restrictions. All data generated or analyzed during this study are included in this published article.

\section{Competing interests}

The authors declare that they have no conflict of interest to report.

\section{Funding}

This study was financially supported by a grant from the Non-Communicable Diseases Research Center, Alborz University of Medical Sciences, Karaj, Iran (Grant No. 1398-1-103-3663).

\section{Authors' Contributions}

Mehrdad Ebrazeh; Performed the experiments, participated in manuscript preparation, and read the manuscript critically.

Fatemeh Ezzatifar, Performed the statistical analysis, participated in manuscript preparation, and read the manuscript critically.

Shahram Torkamandi; Contributed in performing the experiments, participated in manuscript preparation and read the manuscript critically.

Fatemeh Sadat Mohammadi; Introduced the patients, participated in manuscript preparation, and read the manuscript critically.

Sevda Salimifard; Concucted graphical illustrations, participated in manuscript preparation and read the manuscript critically.

Maryam Hemmatzadeh; Participated in manuscript preparation and read the manuscript critically.

Saeed Aslani; Participated in manuscript preparation and read the manuscript critically. 
Farhad Babaie; Participated in manuscript preparation and read the manuscript critically.

Gholamreza Azizi; Participated in manuscript preparation and read the manuscript critically.

Farhad Jadidi-Niaragh; Participated in manuscript preparation and read the manuscript critically.

Arezoo Gowhari-Shabgah; Participated in manuscript preparation and read the manuscript critically.

Hamed Mohammadi; Developed the main idea, take the financial support, participated in manuscript preparation and read the manuscript critically.

\section{Acknowledgements}

The authors are grateful of the patients and the healthy individuals for their participation in the study.

\section{Abbreviations}

SNPs; Single nucleotide polymorphisms, ERAP; Endoplasmic reticulum aminopeptidase, PBMCs; Peripheral blood mononuclear cells, IL; Interleukin, TGF; Transforming growth factor, HLA; human leukocyte antigen, AS; Ankylosing spondylitis, ER: Endoplasmic reticulum, MHC; Major histocompatibility complex, LD; Linkage disequilibrium, BASDAl; Bath AS Disease Activity Index, BASFI; Bath AS Functional Index, BASMI; Bath AS Metrology Index, BASG; Bath AS Global Score, ASQoL; AS quality of life, ELISA; Enzyme linked immunosorbent assay, $\chi 2$; Chi square, OR; Odds ratios, $\mathrm{Cl}$; Confidence intervals, $\mathrm{HWE}$; Hardy-Weinberg Equilibrium, SD; Standard deviation, FHC; Free heavy chain, UPR; Unfolded protein response, APCs; Antigen presenting cells, Th; T helper, IL-23R; IL-23 receptor, TNF; Tumor necrosis factor, IFN; Interferon

\section{References}

1. Sieper J, Braun J, Rudwaleit M, Boonen A, Zink A. Ankylosing spondylitis an overview. Ann Rheum Dis. England. 2002;61(sSuppl 3).

2. Garshasbi M, Mahmoudi M, Razmara E, Vojdanian M, Aslani S, Farhadi E, et al. Identification of RELN variant p.(Ser2486Gly) in an Iranian family with ankylosing spondylitis; the first association of RELN and AS. European Journal of Human Genetics. 2020:1-9.

3. Brown MA, Kenna T, Wordsworth BP. Genetics of ankylosing spondylitis-insights into pathogenesis. Nature Reviews Rheumatology. 2016;12(2):81.

4. Mahmoudi M, Aslani S, Nicknam MH, Karami J, Jamshidi AR. New insights toward the pathogenesis of ankylosing spondylitis; genetic variations and epigenetic modifications. Modern rheumatology. 2017;27(2):198-209.

5. Mohammadi H, Hemmatzadeh M, Babaie F, Gowhari Shabgah A, Azizi G, Hosseini F, et al. MicroRNA implications in the etiopathogenesis of ankylosing spondylitis. Journal of cellular physiology. 2018;233(8):5564-73. 
6. Aslani S, Mahmoudi M, Garshasbi M, Jamshidi AR, Karami J, Nicknam MH. Evaluation of DNMT1 gene expression profile and methylation of its promoter region in patients with ankylosing spondylitis. Clinical rheumatology. 2016;35(11):2723-31.

7. Karami J, Mahmoudi M, Amirzargar A, Gharshasbi M, Jamshidi A, Aslani S, et al. Promoter hypermethylation of BCL11B gene correlates with downregulation of gene transcription in ankylosing spondylitis patients. Genes \& Immunity. 2017;18(3):170-5.

8. Babaie F, Hasankhani M, Mohammadi H, Safarzadeh E, Rezaiemanesh A, Salimi R, et al. The role of gut microbiota and IL-23/IL-17 pathway in ankylosing spondylitis immunopathogenesis: New insights and updates. Immunology letters. 2018;196:52-62.

9. Dashti N, Mahmoudi M, Aslani S, Jamshidi A. HLA-B* 27 subtypes and their implications in the pathogenesis of ankylosing spondylitis. Gene. 2018;670:15-21.

10. Smith JA, Märker-Hermann E, Colbert RA. Pathogenesis of ankylosing spondylitis: current concepts. Best practice \& research Clinical rheumatology. 2006;20(3):571-91.

11. Saric T, Chang S-C, Hattori A, York IA, Markant S, Rock KL, et al. An IFN-y-induced aminopeptidase in the ER, ERAP1, trims precursors to MHC class I-presented peptides. Nature immunology. 2002;3(12):1169.

12. Burton PR, Clayton DG, Cardon LR, Craddock N, Deloukas P, Duncanson A, et al. Association scan of 14,500 nonsynonymous SNPs in four diseases identifies autoimmunity variants. Nature genetics. 2007;39(11):1329.

13. Davidson SI, Wu X, Liu Y, Wei M, Danoy PA, Thomas G, et al. Association of ERAP1, but not IL23R, with ankylosing spondylitis in a Han Chinese population. Arthritis \& Rheumatology. 2009;60(11):3263-8.

14. Cortes A, Hadler J, Pointon JP, Robinson PC, Karaderi T, Leo P, et al. Identification of multiple risk variants for ankylosing spondylitis through high-density genotyping of immune-related loci. Nature genetics. 2013;45(7):730.

15. Andrés AM, Dennis MY, Kretzschmar WW, Cannons JL, Lee-Lin S-Q, Hurle B, et al. Balancing selection maintains a form of ERAP2 that undergoes nonsense-mediated decay and affects antigen presentation. PLoS genetics. 2010;6(10).

16. Evnouchidou I, Birtley J, Seregin S, Papakyriakou A, Zervoudi E, Samiotaki M, et al. A common single nucleotide polymorphism in endoplasmic reticulum aminopeptidase 2 induces a specificity switch that leads to altered antigen processing. The Journal of Immunology. 2012;189(5):2383-92.

17. Johnson MP, Roten LT, Dyer TD, East CE, Forsmo S, Blangero J, et al. The ERAP2 gene is associated with preeclampsia in Australian and Norwegian populations. Human genetics. 2009;126(5):655-66.

18. Mohammadi H, Babaie F, Hemmatzadeh M, Azizi G, Hajaliloo M, Ebrahimi AA, et al. Evaluation of ERAP1 gene single nucleotide polymorphism in impressing the inflammatory cytokine profile of ankylosing spondylitis patients. Iranian Journal of Allergy, Asthma and Immunology. 2018;17(5):46474. 
19. Babaie F, Mohammadi H, Hemmatzadeh M, Ebrazeh M, Torkamandi S, Yousefi M, et al. Evaluation of ERAP1 gene single nucleotide polymorphisms in immunomodulation of pro-inflammatory and antiinflammatory cytokines profile in ankylosing spondylitis. Immunology letters. 2020;217:31-8.

20. Hemmatzadeh M, Babaie F, Ezzatifar F, Mohammadi FS, Ebrazeh M, Golabi Aghdam S, et al. Susceptibility to ERAP1 gene single nucleotide polymorphism modulates the inflammatory cytokine setting in ankylosing spondylitis. International journal of rheumatic diseases. 2019;22(4):715-24.

21. Babaie F, Ebrazeh M, Hemmatzadeh M, Mohammadi FS, Shabgah AG, Hajaliloo M, et al. Association analysis of ERAP1 gene single nucleotide polymorphism in susceptibility to ankylosing spondylitis in Iranian population. Immunology letters. 2018;201:52-8.

22. Ebrazeh M, Nojavan M, Abdi-Shayan S, Salimifard S, Dolatshahi E, Aslani S, et al. Endoplasmic reticulum aminopeptidase 2 gene single nucleotide polymorphisms in association with susceptibility to ankylosing spondylitis in an Iranian population. Immunology Letters. 2020.

23. Van Der Linden S, Valkenburg HA, Cats A. Evaluation of diagnostic criteria for ankylosing spondylitis. Arthritis \& Rheumatism. 1984;27(4):361-8.

24. Schmittgen TD, Livak KJ. Analyzing real-time PCR data by the comparative CT method. Nature protocols. 2008;3(6):1101-8.

25. Yong $Y$, Lin H. SHEsis, a powerful software platform for analyses of linkage disequilibrium, haplotype construction, and genetic association at polymorphism loci. Cell research. 2005;15(2):97-8.

26. Babaie F, Hosseinzadeh R, Ebrazeh M, Seyfizadeh N, Aslani S, Salimi S, et al. The roles of ERAP1 and ERAP2 in autoimmunity and cancer immunity: New insights and perspective. Molecular Immunology. 2020;121:7-19.

27. Kenna TJ, Robinson PC, Haroon N. Endoplasmic reticulum aminopeptidases in the pathogenesis of ankylosing spondylitis. Rheumatology. 2015;54(9):1549-56.

28. Harvey D, Pointon JJ, Karaderi T, Appleton LH, Farrar C, Wordsworth BP. A common functional variant of endoplasmic reticulum aminopeptidase 2 (ERAP2) that reduces major histocompatibility complex class I expression is not associated with ankylosing spondylitis. Rheumatology. 2011;50(9):1720-1.

29. Tsui FW, Haroon N, Reveille JD, Rahman P, Chiu B, Tsui HW, et al. Association of an ERAP1 ERAP2 haplotype with familial ankylosing spondylitis. Annals of the rheumatic diseases. 2010;69(4):733-6.

30. Warthan MD, Washington SL, Franzese SE, Ramus RM, Kim K-R, York TP, et al. The role of endoplasmic reticulum aminopeptidase 2 in modulating immune detection of choriocarcinoma. Biology of reproduction. 2018;98(3):309-22.

31. Vitulano C, Tedeschi V, Paladini F, Sorrentino R, Fiorillo M. The interplay between HLA-B27 and ERAP1/ERAP2 aminopeptidases: from anti-viral protection to spondyloarthritis. Clinical \& Experimental Immunology. 2017;190(3):281-90.

32. Robinson PC, Costello M-E, Leo P, Bradbury LA, Hollis K, Cortes A, et al. ERAP2 is associated with ankylosing spondylitis in HLA-B27-positive and HLA-B27-negative patients. Annals of the rheumatic diseases. 2015;74(8):1627-9. 
33. Martín-Esteban A, Guasp P, Barnea E, Admon A, López de Castro JA. Functional interaction of the ankylosing spondylitis-associated endoplasmic reticulum aminopeptidase 2 with the HLA-B* 27 peptidome in human cells. Arthritis \& rheumatology. 2016;68(10):2466-75.

34. Martín-Esteban A, Sanz-Bravo A, Guasp P, Barnea E, Admon A, de Castro JAL. Separate effects of the ankylosing spondylitis associated ERAP1 and ERAP2 aminopeptidases determine the influence of their combined phenotype on the HLA-B* 27 peptidome. Journal of autoimmunity. 2017;79:28-38.

35. Popa OM, Cherciu M, Cherciu LI, Dutescu MI, Bojinca M, Bojinca V, et al. ERAP1 and ERAP2 gene variations influence the risk of psoriatic arthritis in romanian population. Archivum immunologiae et therapiae experimentalis. 2016;64(1):123-9.

36. Robinson PC, Lau E, Keith P, Lau MC, Thomas GP, Bradbury LA, et al. ERAP2 functional knockout in humans does not alter surface heavy chains or HLA-B27, inflammatory cytokines or endoplasmic reticulum stress markers. Annals of the rheumatic diseases. 2015;74(11):2092-5.

37. Zhang Z, Ciccia F, Zeng F, Guggino G, Yee K, Abdullah H, et al. Brief Report: Functional Interaction of Endoplasmic Reticulum Aminopeptidase 2 and HLA-B27 Activates the Unfolded Protein Response. Arthritis \& Rheumatology. 2017;69(5):1009-15.

38. Schröder M, Kaufman RJ. The mammalian unfolded protein response. Annu Rev Biochem. 2005;74:739-89.

39. Bowness P, Ridley A, Shaw J, Chan AT, Wong-Baeza I, Fleming M, et al. Th17 cells expressing KIR3DL2+ and responsive to HLA-B27 homodimers are increased in ankylosing spondylitis. The Journal of Immunology. 2011;186(4):2672-80.

\section{Tables}


Table 1

Baseline characteristics and clinical manifestations of AS patients and healthy controls.

\begin{tabular}{|llll|}
\hline Characteristic & AS Patients $(\mathrm{n}=250)$ & Healthy controls $(\mathrm{n}=250)$ & $P$ value \\
\hline Age (years) & $38.50 \pm 8.80$ & $37.62 \pm 7.40$ & $>0.05$ \\
\hline Female/Male, $\mathrm{n}(\%)$ & $53(21.2 \%) / 197(78.8 \%)$ & $45(18 \%) / 205(82 \%)$ & $>0.05$ \\
\hline HLA-B27 positive, no (\%) & $202(80.8 \%)$ & $18(7.2 \%)$ & $<0.0001$ \\
\hline CRP (mg/L) & $3.14 \pm 2.27$ & $1.27 \pm 0.95$ & - \\
\hline Disease duration (years) & $10.79 \pm 7.88$ & - & - \\
\hline BASDAl score & $5.34 \pm 3.57$ & - & - \\
\hline BASFI score & $3.45 \pm 2.36$ & - & - \\
\hline BASG score & $4.45 \pm 2.08$ & & - \\
\hline $\begin{array}{l}\text { ASQoL score } \\
\text { HLA; Human leukocyte antigen, CRP; C-reactive protein, BASDAl; Bath ankylosing spondylitis disease } \\
\text { activity index, BASFl; Bath ankylosing spondylitis functional index, BASG; Bath ankylosing spondylitis } \\
\text { global score, ASQoL; Ankylosing spondylitis quality of life }\end{array}$ &
\end{tabular}


Table 2

Sequence of the primers used for mRNA expression of cytokines.

\begin{tabular}{|c|c|c|c|}
\hline \multicolumn{3}{|c|}{ Gene nameSequence of nucleotides $\left(5^{\prime}-3^{\prime}\right)$} & \multirow{2}{*}{$\begin{array}{l}\text { Size (bp) } \\
115\end{array}$} \\
\hline |L-23 & Forward & AGTGGAAGTGGGCAGAGATTC & \\
\hline & Reverse & CAGCAGCAACAGCAGCATTAC & \\
\hline \multirow[t]{2}{*}{ IL-17A } & Forward & СTCTGTGATCTGGGAGGCAAAG & 196 \\
\hline & Reverse & GACAATCGGGGTGACACAGG & \\
\hline \multirow[t]{2}{*}{ |L-10 } & Forward & AGCTGAGAACCAAGACCCAGAC & $c 72$ \\
\hline & Reverse & AAGAAATCGATGACAGCGCC & \\
\hline \multirow[t]{2}{*}{ TGF- $\beta$} & Forward & GCAACAATTCCTGGCGATACCT & 222 \\
\hline & Reverse & TCCCCTCCACGGCTCAAC & \\
\hline \multirow[t]{2}{*}{$\beta$-Actin } & \multicolumn{2}{|c|}{ ACTB - ForwardGGTCCTCACTGCCTGTCC } & 140 \\
\hline & \multicolumn{2}{|c|}{ ACTB - ReverseCTCGTCATACTCCTGCTTGCT } & \\
\hline
\end{tabular}


Table 3

Allele and genotype frequencies of ERAP2 gene rs2548538, rs2287988, and rs 17408150 SNPs in AS patients and healthy controls and corresponding association analyses.

\begin{tabular}{|c|c|c|c|c|c|c|}
\hline \multirow[t]{2}{*}{ SNP* } & \multirow[t]{2}{*}{ Allele /Genotype } & \multirow{2}{*}{$\begin{array}{l}A S^{*}(n=250) \\
N \%\end{array}$} & \multirow{2}{*}{$\begin{array}{l}\text { Control }(n=250) \\
N \%\end{array}$} & \multirow[t]{2}{*}{$\mathrm{OR}^{\star}\left(95 \% \mathrm{Cl}^{\star}\right)$} & \multirow[t]{2}{*}{$P$} & \multirow[t]{2}{*}{ Adjusted $P^{\star \star}$} \\
\hline & & & & & & \\
\hline \multirow[t]{7}{*}{ rs2548538 } & T vs. A & $186(37.2)$ & $197(39.4)$ & $0.91(0.70-1.17)$ & 0.47 & - \\
\hline & A (Reference) & $314(62.8)$ & $303(60.6)$ & - & - & - \\
\hline & TT vs. AA & $32(12.8)$ & $38(15.2)$ & $0.79(0.46-1.38)$ & 0.42 & 0.81 \\
\hline & TA vs. AA & $122(48.8)$ & $121(48.4)$ & $0.95(0.65-1.39)$ & 0.81 & 0.81 \\
\hline & $\mathrm{TT} v s . \mathrm{TA}+\mathrm{AA}$ & $32(12.8)$ & $38(15.2)$ & $0.81(0.49-1.35)$ & 0.43 & 0.81 \\
\hline & $\mathrm{TT}+\mathrm{TA} v s . \mathrm{AA}$ & $154(61.6)$ & 159 (63.6) & $0.91(0.63-1.31)$ & 0.64 & 0.81 \\
\hline & AA (Reference) & $96(38.4)$ & $91(36.4)$ & - & - & - \\
\hline HWE* & & & $P=0.830$ & & & \\
\hline \multirow[t]{7}{*}{ rs2287988 } & G vs. A & $217(43.4)$ & $192(38.4)$ & $1.23(0.95-1.58)$ & 0.11 & - \\
\hline & A (Reference) & $283(56.6)$ & $308(61.6)$ & - & - & - \\
\hline & GG vs. AA & $47(18.8)$ & 34 (13.6) & $1.58(0.93-2.71)$ & 0.66 & 0.66 \\
\hline & GA vs. AA & $123(49.2)$ & $124(49.6)$ & $1.47(0.77-1.68)$ & 0.50 & 0.66 \\
\hline & $\mathrm{GG} v s . \mathrm{GA}+\mathrm{AA}$ & $47(18.8)$ & $34(13.6)$ & $0.80(0.90-2.37)$ & 0.12 & 0.48 \\
\hline & $G G+G A v s . A A$ & $170(68.0)$ & $158(63.2)$ & $1.23(0.85-1.79)$ & 0.25 & 0.50 \\
\hline & AA (Reference) & $80(32.0)$ & $92(36.8)$ & - & - & - \\
\hline HWE & & & $P=0.443$ & & & \\
\hline \multirow[t]{4}{*}{ rs17408150 } & A vs. T & $242(48.4)$ & $220(44.0)$ & $1.98(0.93-1.53)$ & 0.16 & - \\
\hline & $\mathrm{T}$ (Reference) & $258(51.6)$ & $280(56.0)$ & - & - & - \\
\hline & AA vs. TT & $49(19.6)$ & $43(17.2)$ & $1.45(0.85-2.49)$ & 0.17 & 0.20 \\
\hline & AT $v s$. TT & $144(57.6)$ & 134 (53.6) & $1.37(0.90-2.09)$ & 0.14 & 0.20 \\
\hline
\end{tabular}

*SNP; single nucleotide polymorphism, AS; ankylosing spondylitis, OR; odds ratio, $95 \% \mathrm{Cl} ; 95 \%$ confidence interval, HWE; Hardy-Weinberg equilibrium 


\begin{tabular}{|c|c|c|c|c|c|c|}
\hline \multirow[t]{4}{*}{ SNP* } & Allele /Genotype & $\begin{array}{l}A S *(n=250) \\
N \%\end{array}$ & $\begin{array}{l}\text { Control }(n=250) \\
N \%\end{array}$ & $\mathrm{OR}^{\star}\left(95 \% \mathrm{Cl} \mathrm{I}^{\star}\right)$ & $P$ & Adjusted $P^{* *}$ \\
\hline & $\mathrm{AA} v s . \mathrm{AT}+\mathrm{TT}$ & $49(19.6)$ & $43(17.2)$ & $1.31(0.86-1.99)$ & 0.20 & 0.20 \\
\hline & $\mathrm{AA}+\mathrm{AT} v s . \mathrm{TT}$ & 193 (77.2) & $177(70.8)$ & $1.39(0.93-2.08)$ & 0.10 & 0.20 \\
\hline & TT (Reference) & $57(22.8)$ & $73(29.2)$ & - & - & - \\
\hline HWE & & & $P=0.165$ & & & \\
\hline
\end{tabular}


Table 4

Allele and genotype frequencies of ERAP2 gene rs2548538, rs2287988, and rs 17408150 SNPs in HLA-B27 positive AS patients and healthy controls.

\begin{tabular}{|c|c|c|c|c|c|}
\hline \multirow[t]{3}{*}{ SNP* } & \multirow{3}{*}{$\begin{array}{l}\text { Allele } \\
\text { /Genotype }\end{array}$} & HLA-B27 Positive AS* $(n=$ & Control $(n=$ & \multirow[t]{3}{*}{$\mathrm{OR}^{*}\left(95 \% \mathrm{Cl}^{\star}\right)$} & \multirow[t]{3}{*}{$P \quad$ Adjusted $P^{\star \star}$} \\
\hline & & 202) & 250) & & \\
\hline & & $\mathrm{N} \%$ & $\mathrm{~N} \%$ & & \\
\hline \multirow[t]{12}{*}{ rs2548538 } & T vs. A & 167 (41.3) & 197 (39.4) & $1.08(0.82-$ & \multirow[t]{2}{*}{$0.465-$} \\
\hline & & & & 1.41) & \\
\hline & A (Reference) & $237(58.7)$ & $303(60.6)$ & - & - \\
\hline & TT $v s . \mathrm{AA}$ & $27(13.3)$ & 38 (15.2) & $1.04(0.57-$ & \multirow[t]{2}{*}{0.8770 .87} \\
\hline & & & & 1.88) & \\
\hline & TA vs. AA & $113(55.9)$ & $121(48.4)$ & $1.37(0.90-$ & \multirow[t]{2}{*}{0.1340 .40} \\
\hline & & & & 2.07) & \\
\hline & TT $v s . \mathrm{TA}+\mathrm{AA}$ & $27(13.3)$ & 38 (15.2) & $0.86(0.50-$ & \multirow[t]{2}{*}{0.5740 .76} \\
\hline & & & & 1.46) & \\
\hline & $\mathrm{TT}+\mathrm{TA} v s . \mathrm{AA}$ & 140 (69.3) & $159(63.6)$ & $1.29(0.87-$ & \multirow[t]{2}{*}{0.2010 .40} \\
\hline & & & & 1.91) & \\
\hline & AA (Reference) & $62(30.7)$ & $91(36.4)$ & - & - \\
\hline \multicolumn{3}{|l|}{ HWE* } & \multicolumn{3}{|l|}{$P=0.830$} \\
\hline \multirow[t]{8}{*}{ rs2287988 } & G vs. A & $185(45.7)$ & $192(38.4)$ & $1.35(1.03-$ & \multirow[t]{2}{*}{$0.023-$} \\
\hline & & & & 1.76) & \\
\hline & A (Reference) & 219 (54.2) & 308 (61.6) & - & - \\
\hline & GG vs. AA & $41(20.3)$ & $34(13.6)$ & $1.91(1.09-$ & \multirow[t]{2}{*}{0.0220 .08} \\
\hline & & & & 3.35) & \\
\hline & GA vs. AA & 103 (50.9) & $124(49.6)$ & \multicolumn{2}{|c|}{$1.31(0.86-2.00) 0.1910 .19$} \\
\hline & GG vs. GA + AA & $41(20.3)$ & $34(13.6)$ & $1.61(0.98-$ & \multirow[t]{2}{*}{0.0550 .09} \\
\hline & & & & $2.66)$ & \\
\hline
\end{tabular}

`SNP; single nucleotide polymorphism, HLA-B27; Human leukocyte antigen-B27, AS; ankylosing spondylitis, OR; odds ratio, 95\% Cl; 95\% confidence interval, HWE; Hardy-Weinberg equilibrium «*FDR correction for multiple comparisons by Benjamini-Hochberg 


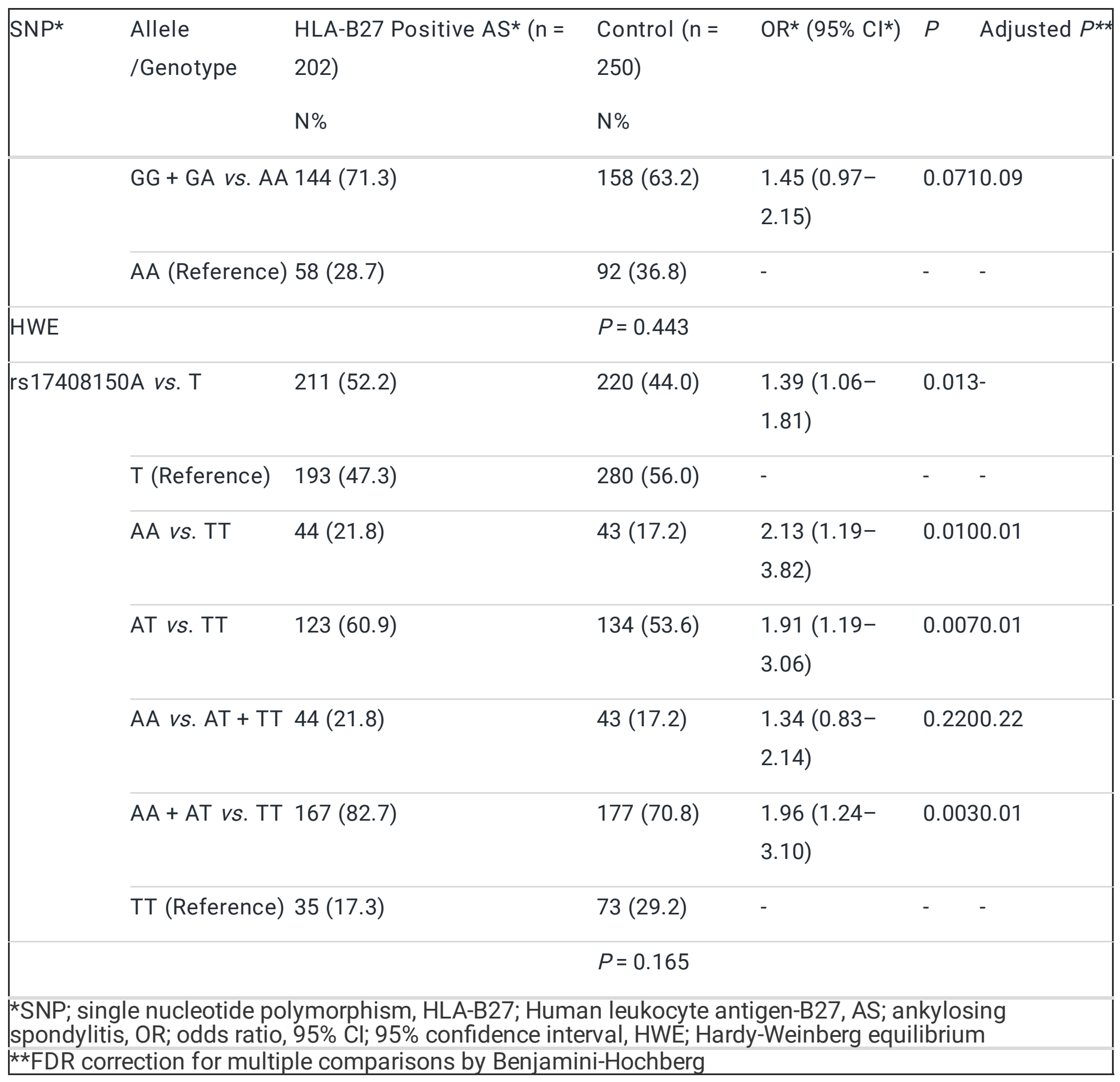


Table 5

haplotype association of ERAP2 gene rs2548538, rs2287988, and rs 17408150 SNPs according to Haploview.

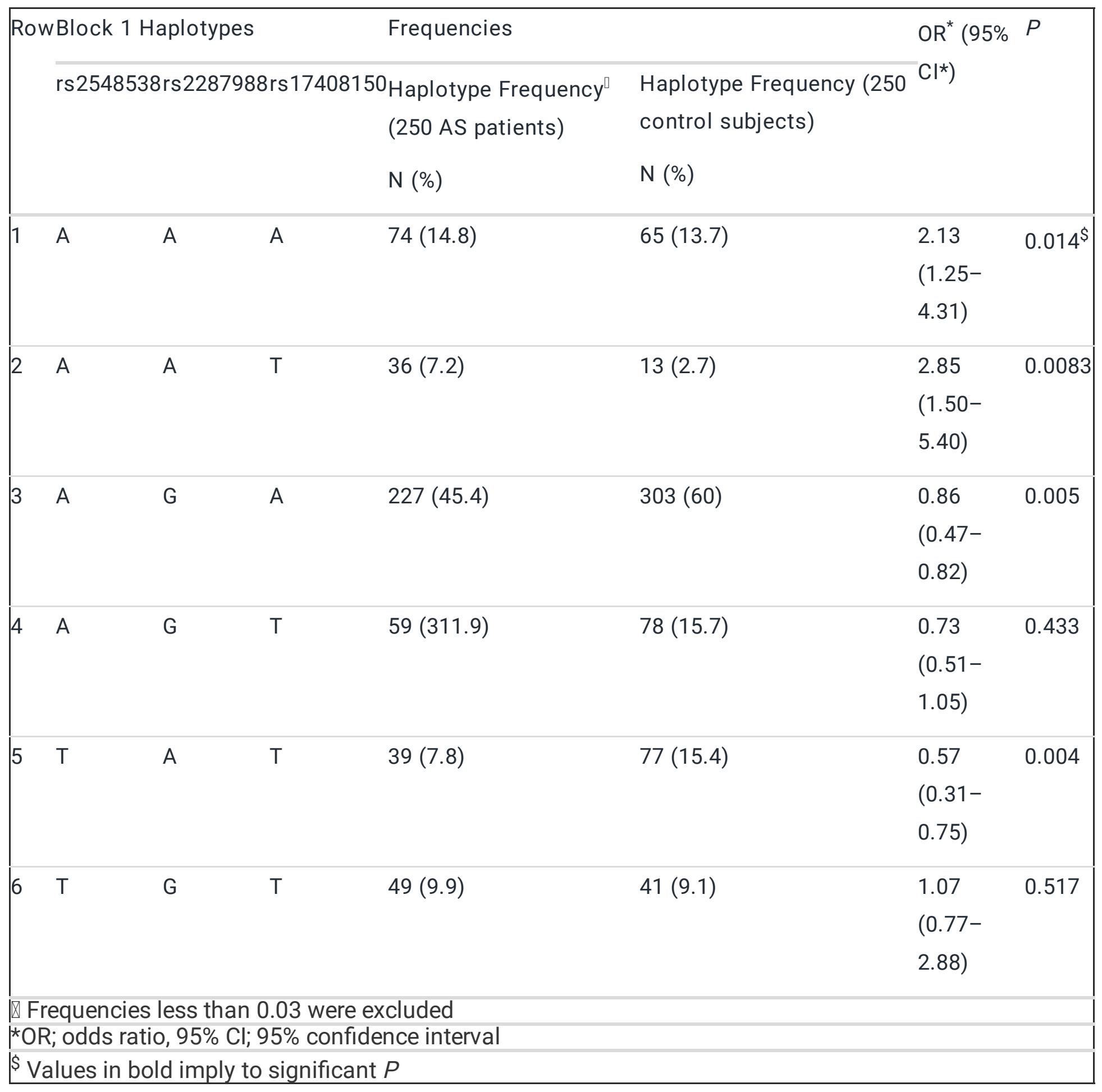


Table 6

Association of ERAP2 gene rs $2548538, \mathrm{rs} 2287988$, and rs 17408150 SNPs with clinical manifestations of AS patients $(n=250)$.

\begin{tabular}{|c|c|c|c|c|}
\hline Characteristic & rs2548538 (TT) & rs2548538 (TA) & rs2548538 (AA) & $P$ value \\
\hline Disease duration (years) & $10.37 \pm 2.91$ & $10.71 \pm 3.63$ & $10.55 \pm 3.05$ & 0.388 \\
\hline $\mathrm{CRP}(\mathrm{mg} / \mathrm{L})$ & $3.25 \pm 3.10$ & $3.11 \pm 3.41$ & $3.44 \pm 3.75$ & 0.655 \\
\hline BASDAI score & $5.21 \pm 3.44$ & $4.46 \pm 2.88$ & $4.46 \pm 2.43$ & 0.266 \\
\hline BASFI score & $3.11 \pm 2.49$ & $3.56 \pm 2.16$ & $3.64 \pm 2.15$ & 0.385 \\
\hline BASG score & $4.05 \pm 3.11$ & $5.28 \pm 2.43$ & $4.55 \pm 2.76$ & 0.455 \\
\hline \multirow[t]{2}{*}{ ASQoL score } & $6.89 \pm 3.28$ & $7.80 \pm 4.15$ & $7.86 \pm 3.54$ & 0.390 \\
\hline & rs2287988 (GG) & rs2287988 (GA) & rs2287988 (AA) & $\boldsymbol{P}$ value \\
\hline Disease duration (years) & $9.88 \pm 4.14$ & $10.74 \pm 3.75$ & $10.22 \pm 4.69$ & 0.256 \\
\hline CRP (mg/L) & $3.15 \pm 2.57$ & $3.62 \pm 2.41$ & $3.11 \pm 2.50$ & 0.399 \\
\hline BASDAI score & $4.66 \pm 2.19$ & $4.11 \pm 2.45$ & $5.74 \pm 2.48$ & 0.313 \\
\hline BASFI score & $3.85 \pm 2.08$ & $3.18 \pm 2.39$ & $3.44 \pm 2.76$ & 0.746 \\
\hline BASG score & $4.57 \pm 2.30$ & $4.61 \pm 2.20$ & $5.18 \pm 2.47$ & 0.287 \\
\hline \multirow[t]{2}{*}{ ASQoL score } & $7.18 \pm 3.65$ & $6.98 \pm 3.27$ & $7.55 \pm 5.40$ & 0.818 \\
\hline & rs $17408150(A A)$ & rs 17408150 (AT) & rs $17408150(\mathrm{TT})$ & $\boldsymbol{P}$ value \\
\hline Disease duration (years) & $10.24 \pm 3.79$ & $9.70 \pm 3.87$ & $10.47 \pm 4.08$ & 0.213 \\
\hline CRP (mg/L) & $3.28 \pm 2.23$ & $3.07 \pm 2.63$ & $4.54 \pm 2.75$ & 0.711 \\
\hline BASDAI score & $5.41 \pm 2.16$ & $4.12 \pm 2.44$ & $4.85 \pm 2.11$ & 0.570 \\
\hline BASFI score & $3.25 \pm 2.61$ & $2.82 \pm 2.85$ & $3.35 \pm 2.84$ & 0.597 \\
\hline BASG score & $4.11 \pm 2.38$ & $5.14 \pm 2.42$ & $5.71 \pm 2.38$ & 0.423 \\
\hline ASQoL score & $7.55 \pm 4.82$ & $7.35 \pm 5.61$ & $6.47 \pm 2.63$ & 0.646 \\
\hline
\end{tabular}

Figures 


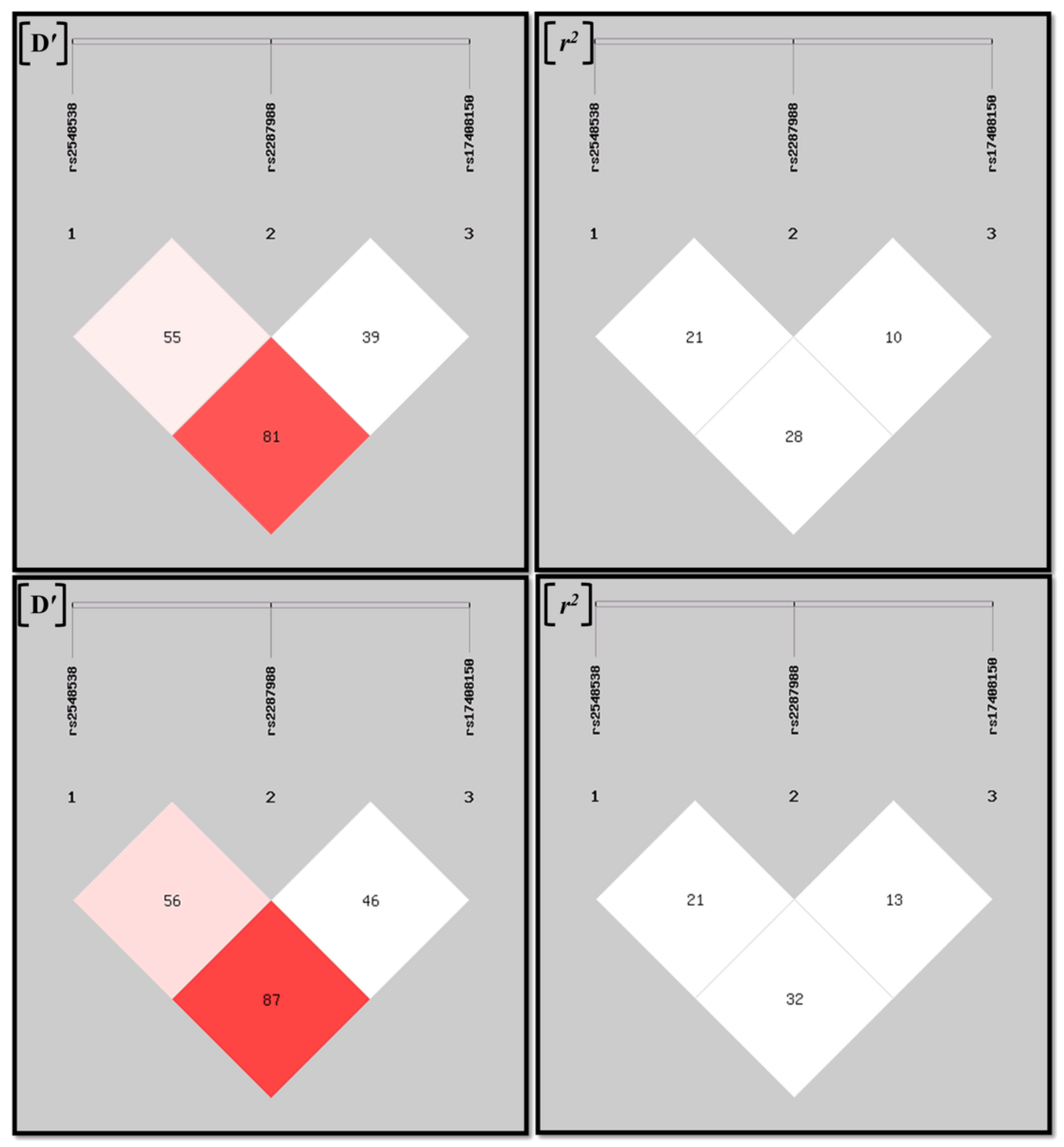

Figure 1

Bar charts show the relative mRNA amounts of IL-17A, IL-23, IL-10, and TGF- $\beta$ in the study groups (a, b, c, d). The comparison of the relative mRNA levels of cytokines in the AS patients with three genotypes for rs2287988 SNP (e, f, g, h). Relative transcription level of the cytokines in the AS patients harboring three different genotypes for rs17408150 SNP $(I, j, k, I)$. The mean comparisons were conducted by statistical tests of Mann-Whitney's U or Kruskal-Wallis (** shows $\mathrm{P}<0.01$, *** shows $\mathrm{P}<0.001$ ). 

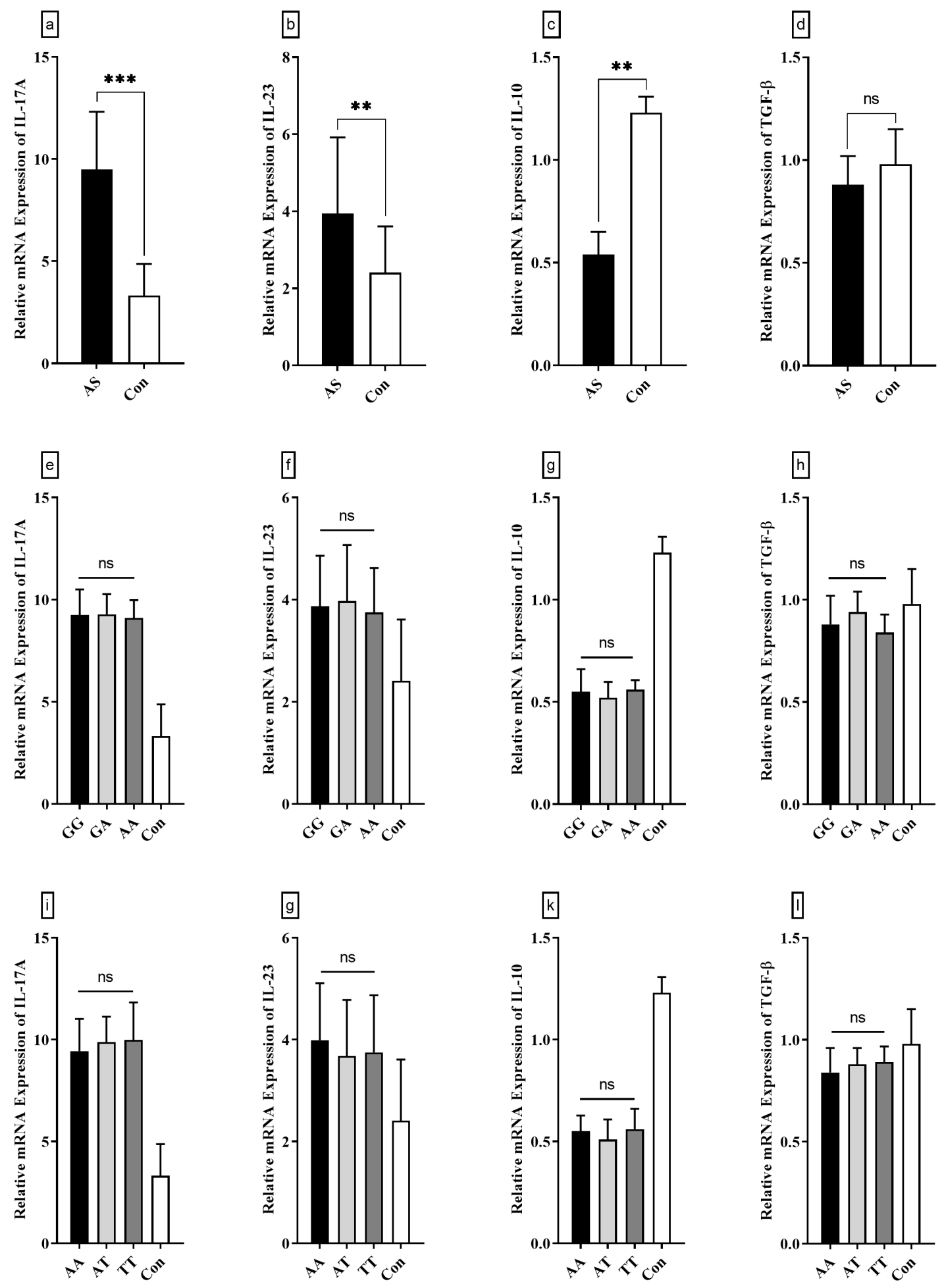

Figure 2

Bar charts show the relative mRNA amounts of IL-17A, IL-23, IL-10, and TGF- $\beta$ in the study groups $(a, b, c$, d). The comparison of the relative mRNA levels of cytokines in the AS patients with three genotypes for rs2287988 SNP (e, f, g, h). Relative transcription level of the cytokines in the AS patients harboring three different genotypes for rs 17408150 SNP $(I, j, k, I)$. The mean comparisons were conducted by statistical tests of Mann-Whitney's U or Kruskal-Wallis (** shows $\mathrm{P}<0.01$, *** shows $\mathrm{P}<0.001$ ). 

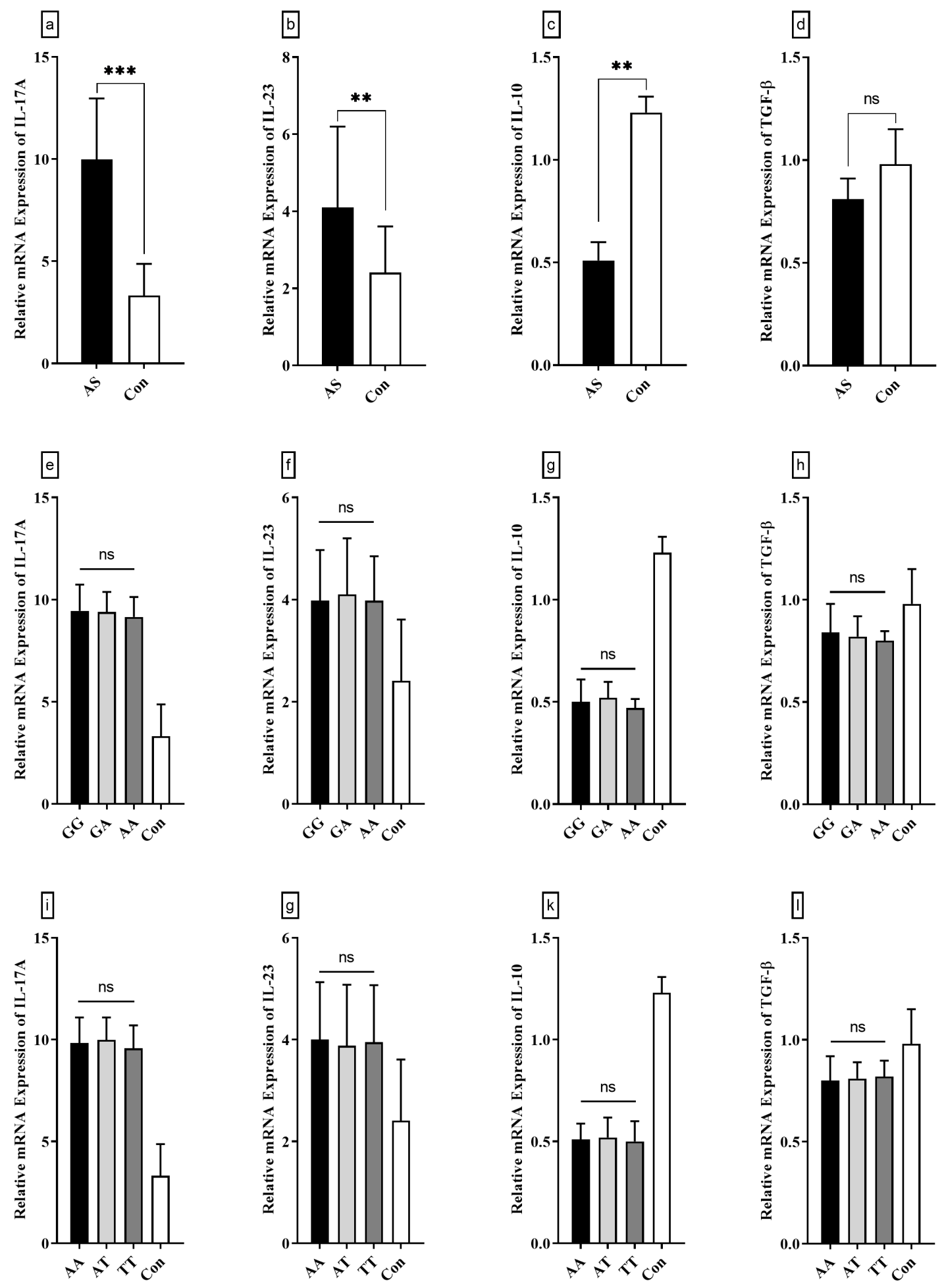

Figure 3

Bar charts show the relative transcriptional amounts of IL-17A, IL-23, IL-10, and TGF- $\beta$ mRNAs in the AS patients positive for HLA-B27 and healthy controls $(a, b, c, d)$. The comparison of the relative mRNA amounts of cytokines in the AS patients positive for HLA-B27 harboring three different for rs2287988 $\operatorname{SNP}(e, f, g, h)$. Relative transcription level of the cytokines in the AS patients positive for HLA-B27 harboring three different genotypes for rs17408150 SNP (I, j, k, I). The mean comparisons were carried 


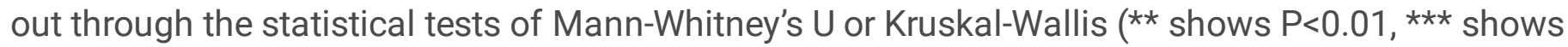
$\mathrm{P}<0.001)$.
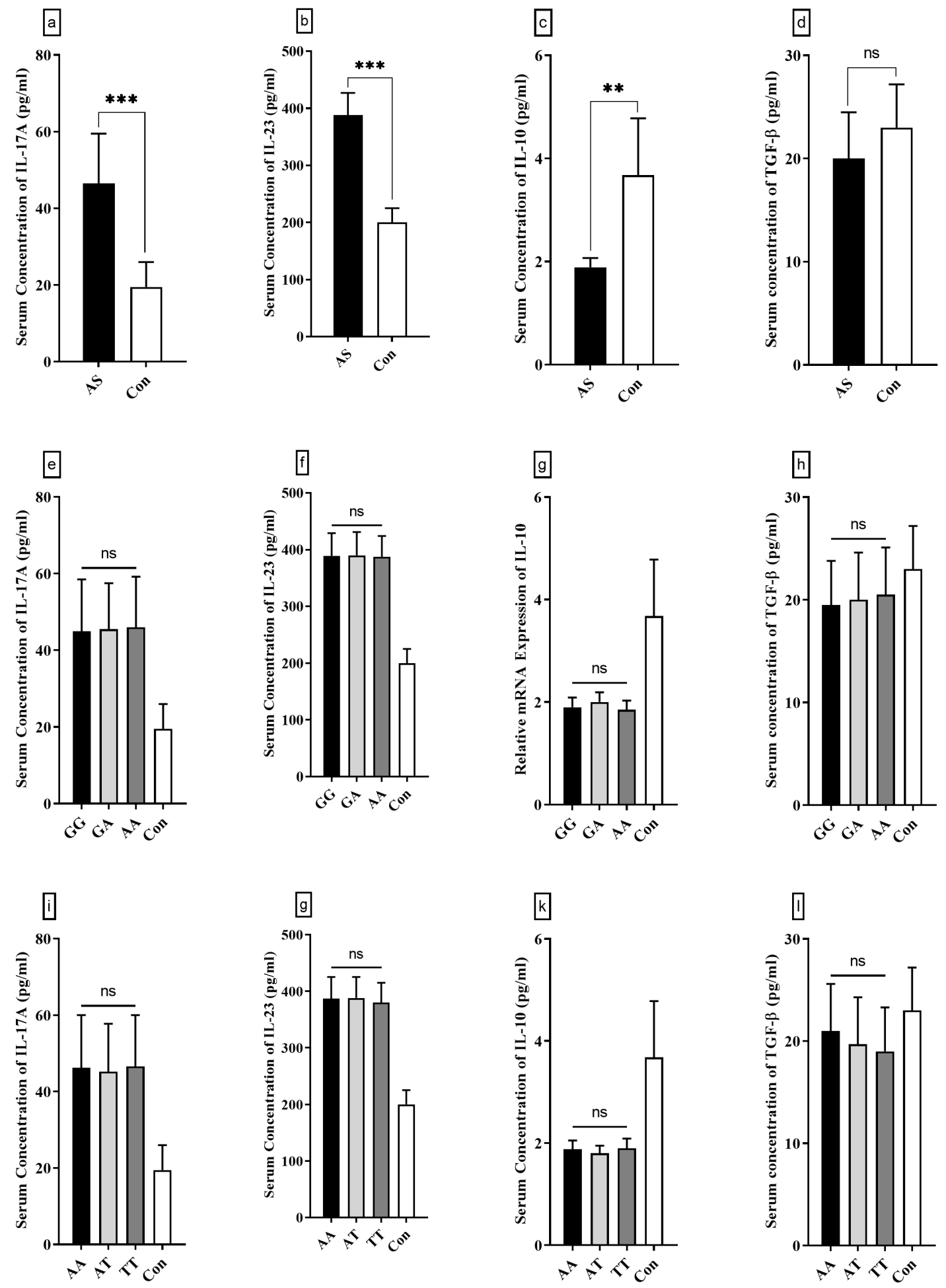

Figure 4

Bar charts depict the serum levels of IL-17A, IL-23, IL-10, and TGF- $\beta$ in the AS patients and normal controls $(a, b, c, d)$. The comparison of the serum levels of cytokines in the AS patients harboring three different genotypes for rs2287988 SNP (e,f, g, h). Serum concentrations the cytokines in the AS patients 
with three genotypes for rs $17408150 \operatorname{SNP}(I, j, k, l)$. The mean comparisons were done by statistical tests of Mann-Whitney's U or Kruskal-Wallis (** shows $\mathrm{P}<0.01$, *** shows $\mathrm{P}<0.001$ ).
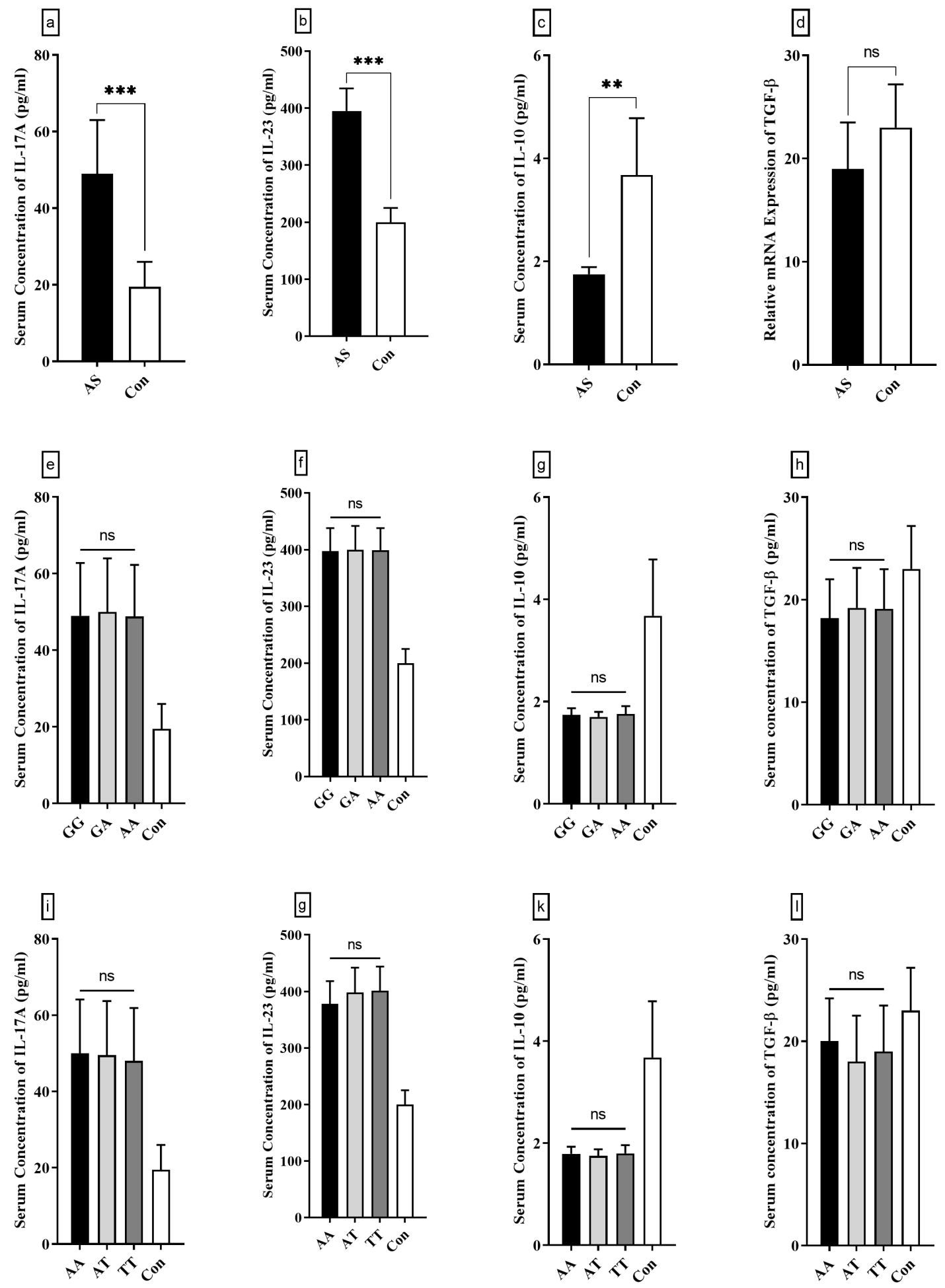

Figure 5

Bar graphs show the levels of IL-17A, IL-23, IL-10, and TGF- $\beta$ in the serum of the AS patients positive for HLA-B27 and normal controls (a, b, c, d). The comparison of the serum levels of cytokines in the AS patients positive for HLA-B27 harboring three different genotypes for rs2287988 SNP (e, f, g, h). Serum 
concentrations of the cytokines in the AS patients positive for HLA-B27harboring three different genotypes for rs17408150 SNP $(I, j, k, l)$. The mean comparisons were done using the statistical tests of Mann-Whitney's $U$ or Kruskal-Wallis ( ${ }^{\star *}$ shows $\mathrm{P}<0.01$, *** shows $\mathrm{P}<0.001$ ).

\section{Supplementary Files}

This is a list of supplementary files associated with this preprint. Click to download.

- SupplementaryTable.docx 